\title{
Effect of Glucose and Long-chain Fatty Acids on Synthesis of Long-chain Alcohols by Candida albicans
}

\author{
By MICHAEL J. WHITE, ${ }^{1}+$ ROGER C. HAMMOND ${ }^{2}$ AND \\ ANTHONY H. ROSE ${ }^{1 *}$ \\ ${ }^{1}$ Zymology Laboratory, School of Biological Sciences, Bath University, \\ Bath BA2 7AY, UK \\ ${ }^{2}$ Unilever Research Laboratory, Colworth Laboratory, Colworth House, Sharnbrook, \\ Bedford MK44 ILQ, UK
}

(Received 26 February 1988)

\begin{abstract}
Candida albicans, grown aerobically in glucose-containing media, produced $\mathrm{C}_{14}, \mathrm{C}_{16}$ and $\mathrm{C}_{18}$ saturated long-chain alcohols only after the end of exponential growth. Contents of $\mathrm{C}_{14}$ alcohols were always lowest, and $\mathrm{C}_{16}$ and $\mathrm{C}_{18}$ alcohol contents about equal. Contents of all three classes of alcohol increased as the concentration of glucose in aerobic cultures harvested after $168 \mathrm{~h}$ incubation was raised from 1.0 to $30.0 \%(\mathrm{w} / \mathrm{v})$. However, in $168 \mathrm{~h}$ anaerobic cultures, greatest long-chain alcohol contents in organisms were obtained using media containing $10 \%(\mathrm{w} / \mathrm{v})$ glucose. Substituting glucose $(10 \%, \mathrm{w} / \mathrm{v})$ with the same concentration of galactose in aerobic cultures greatly decreased contents of long-chain alcohols, while inclusion of $10 \%(w / v)$ glycerol virtually abolished their synthesis. Supplementing anaerobic cultures with odd-chain fatty acids induced synthesis of odd-chain alcohols. Maximum conversion of fatty acid to the corresponding long-chain alcohol was observed with heptadecanoic acid. The effect of glucose on production of heptadecanol from exogenously provided heptadecanoic acid was similar to that observed on synthesis of the three major even-chain alcohols in media lacking a fatty-acid supplement. Cell-free extracts of organisms catalysed in vitro conversion of palmitoyl-CoA to 1-hexadecanol.
\end{abstract}

\section{INTRODUCTION}

A number of micro-organisms are known to synthesize long-chain alcohols. Among prokaryotes, they include mycobacteria (Ratledge, 1976) and other bacteria with the capacity to oxidize alkanes (Ratledge, 1978; Britton, 1984). When grown on carbon sources other than alkanes, some bacteria synthesize long-chain primary alcohols by reduction of CoA esters of long-chain carboxylic acids which arise during endogenous production of fatty-acyl residues (Day et al., 1970; Naccarato et al., 1972; Lloyd \& Russell, 1983) or which are supplied exogenously (Naccarato et al., 1974; Lloyd \& Russell, 1983). Less has been reported on longchain alcohol production by yeasts. Some species can grow on alkanes (Britton, 1984) and certain of these, including Candida guilliermondii (Muratov et al., 1979) and Rhodotorula glutinis (Zalashko et al., 1979; Zalashko \& Salokhina, 1982), may accumulate wax esters containing long-chain alcohols. Davidova et al. (1978) reported briefly that glucose-grown $C$. tropicalis synthesized wax esters, although greater amounts were produced when the yeast was grown on n-octadecane. White et al. (1987) detected unesterified long-chain alcohols in several yeast strains grown on glucose. They screened 14 yeast strains from six genera for ability to synthesize these alcohols, and found that six strains from three genera had this ability, highest levels being

$\dagger$ Present address: Department of Biological Sciences, Carnegie Mellon University, 4400 Fifth Avenue, Pittsburgh, PA 15213-3890, USA. 
found in Candida albicans. The alcohols were predominantly $\mathrm{C}_{14}, \mathrm{C}_{16}$ and $\mathrm{C}_{18}$ saturated primary alcohols; unsaturated alcohols were not detected. Long-chain alcohol synthesis was favoured by anaerobic conditions during growth, and occurred only after the end of exponential growth. The present paper reports on the effect of glucose concentration and exogenous provision of longchain fatty acids on long-chain alcohol synthesis by $C$. albicans grown aerobically or anaerobically.

\section{METHODS}

Organism. The organism used was Candida albicans NCYC 1467, kindly provided by L. Julia Douglas, University of Glasgow, UK, before it was deposited in the collection. It was maintained at $4{ }^{\circ} \mathrm{C}$ on slopes containing $\left(1^{-1}\right)$ : malt extract, $3.0 \mathrm{~g}$; yeast extract (Lab M), $3.0 \mathrm{~g}$; glucose, $10 \mathrm{~g}$; peptone, $0.5 \mathrm{~g}$; and agar, $20 \mathrm{~g}$ (MYGP; Wickerham, 1951).

Experimental cultures. Organisms were grown aerobically or anaerobically in a medium containing $\left(1^{-1}\right)$ : $\left(\mathrm{NH}_{4}\right)_{2} \mathrm{SO}_{4}, 3.0 \mathrm{~g} ; \mathrm{KH}_{2} \mathrm{PO}_{4}, 4.5 \mathrm{~g} ;$ yeast extract $(\mathrm{Lab} \mathrm{M}), 4.0 \mathrm{~g} ; \mathrm{MgSO}_{4} .7 \mathrm{H}_{2} \mathrm{O}, 25 \mathrm{mg}$; and $\mathrm{CaCl}_{2} .2 \mathrm{H}_{2} \mathrm{O}, 25 \mathrm{mg}$ (adjusted to $\mathrm{pH} 4.5$ with $\mathrm{HCl}$ ). Unless otherwise indicated, the carbon source was glucose, at the concentration stated in the text. Portions (1 1 ) of medium were dispensed into 2-litre round flat-bottomed flasks and sterilized by autoclaving at $10 \mathrm{lbf}^{-2}\left(6.89 \times 10^{4} \mathrm{~Pa}\right)$ for $1 \mathrm{~min}$. In certain experiments, the medium was supplemented with a long-chain fatty acid $\left(10 \mathrm{mg} \mathrm{l}^{-1}\right)$ added either as a $1 \mathrm{ml}$ solution in ethanol at the start of growth or $2 \mathrm{mg}(24 \mathrm{~h})^{-1}$ in ethanol to a final concentration of $10 \mathrm{mg} \mathrm{l}^{-1}$ after an initial $24 \mathrm{~h}$ incubation. Starter cultures $(100 \mathrm{ml}$ medium in a $250 \mathrm{ml}$ flask) were inoculated with a pinhead of organisms from a slope culture, and incubated for $48 \mathrm{~h}$ at $30^{\circ} \mathrm{C}$ on an orbital shaker ( 200 r.p.m.). Experimental cultures were inoculated with a portion of starter culture containing $10 \mathrm{mg}$ dry wt organisms, and incubated aerobically or anaerobically as described by White et al. (1987). Growth was followed by measuring optical density at $600 \mathrm{~nm}$, measurements being related to dry wt by a standard curve. At times indicated, organisms were harvested by centrifugation at $6000 \mathrm{~g}$ at $4{ }^{\circ} \mathrm{C}$ and washed twice with water.

Analysis of long-chain alcohols. Methods for extracting lipids from organisms, separating long-chain alcohols from extracts and analysing the alcohols were as described by White et al. (1987).

Preparation and fractionation of cell-free extracts. Anaerobically grown organisms ( $2 \mathrm{~g} \mathrm{dry} \mathrm{wt})$ from $72 \mathrm{~h}$ cultures were washed twice with $100 \mathrm{~mm}$-potassium phosphate buffer (pH 6.5) containing 5 mM-2-mercaptoethanol, suspended in $10 \mathrm{ml}$ buffer and the suspension shaken in a Braun homogenizer for four periods of $30 \mathrm{~s}$ at speed 2 ( $4000 \mathrm{r}$ r.p.m.) with $40 \mathrm{~g}$ glass beads (Sigma type V; 0.45-0.50 mm diameter). During cell disruption, the sample bottle was cooled with expanding $\mathrm{CO}_{2}$. The homogenate was suspended in $120 \mathrm{ml}$ buffer and whole organisms and debris removed by centrifugation at $500 \mathrm{~g}$ for $5 \mathrm{~min}$. The supernatant was centrifuged at $18000 \mathrm{~g}$ for $30 \mathrm{~min}$ to remove mitochondria or promitochondria. A microsomal fraction was obtained by centrifuging the postmitochondrial supernatant at $100000 \mathrm{~g}$ for $90 \mathrm{~min}$ and suspended in $6 \mathrm{ml}$ buffer. Protein in the supernatant obtained after removal of the microsomal fraction was precipitated as described by Naccarato et al. (1974). Ammonium sulphate (heavy-metal-free) was added to the supernatant to give $55 \%$ saturation, the suspension stirred for $15 \mathrm{~min}$ at $4{ }^{\circ} \mathrm{C}$, and the precipitated protein collected by centrifugation at $12000 \mathrm{~g}$ for $20 \mathrm{~min}$. The protein was redissolved in $6 \mathrm{ml}$ buffer. All centrifugations were done at $4^{\circ} \mathrm{C}$.

Enzyme assay of 1-hexadecanol formation. 1-Hexadecanol formation by cell-free fractions was assayed using $\left[{ }^{14} \mathrm{C}\right]$ palmitoyl-CoA. The reaction mixture (final volume $2 \mathrm{ml}$ ), in a $5 \mathrm{ml}$ Reacti-Vial (Pierce), consisted of $100 \mathrm{~mm}-$ potassium phosphate buffer ( $\mathrm{pH} \mathrm{6.5)} \mathrm{containing} 5 \mathrm{~mm}$-2-mercaptoethanol, $2 \mathrm{mg}$ bovine serum albumin (fattyacid-free), $0.3 \mu \mathrm{mol}$ NADH or NADPH, $20 \mathrm{nmol}\left[1{ }^{-14} \mathrm{C}\right]$ palmitoyl-CoA (2.15 GBq mmol ${ }^{-1}$; Amersham) and $2 \mathrm{mg}$ microsomal or soluble protein. The reaction mixture was incubated for $1 \mathrm{~h} \mathrm{at} 30^{\circ} \mathrm{C}$ on an orbital shaker (200 r.p.m.) after the head space had been flushed with nitrogen gas. The reaction was terminated by adding $3 \mathrm{ml}$ methanol, and lipids extracted by adjusting the solvent concentration to $1: 1: 2$ (by vol.) water/methanol/chloroform. 1-Hexadecanol was added as carrier to the extraction solvent such that $25 \mathrm{nmol}$ was present in each reaction mixture. The lower organic phase was removed, concentrated under a stream of nitrogen gas and spotted onto a precoated Silica Gel 60 TLC plate $(20 \mathrm{~cm} \times 20 \mathrm{~cm} \times 0.25 \mathrm{~mm}$ thick; Merck). Plates were developed with a hexane/diethyl ether/acetic acid (30:70:1, by vol.) solvent mixture, and long-chain alcohols removed and prepared for GLC analysis as described by White et al. (1987). A $1 \mu \mathrm{l}$ portion was analysed by GLC to determine the extent of carrier recovery (estimated from the ratio of the peak area of the 1-hexadecanol in the sample to the peak area of the 1-hexadecanol present in the extraction solvent). Radioactivity in the remaining samples was assayed using a LKB 1217 Rackbeta liquid scintillation spectrometer, each vial containing $7.5 \mathrm{ml}$ Optiphase Safe scintillant. The amount of 1 -hexadecanol synthesized was calculated by dividing the corrected radioactivity by the specific activity of the sample substrate.

Protein assay. Protein contents were determined using a dye-binding assay (Bio-Rad). Protein was extracted from the microsomal fraction by boiling a portion $(0.1 \mathrm{ml})$ with an equal volume of $0.1 \mathrm{M}-\mathrm{NaOH}$ for $5 \mathrm{~min}$, then neutralizing with $0.1 \mathrm{M}-\mathrm{HCl}(0.1 \mathrm{ml})$ and $0.2 \mathrm{ml}$ acetic acid/sodium acetate buffer $(0.2 \mathrm{M} ; \mathrm{pH} 5.0)$. Portions $(0.1 \mathrm{ml})$ of protein solution, diluted as necessary, were mixed with Bio-Rad dye reagent $(5 \mathrm{ml} ; 20 \%$, v/v, in water $)$, the 
solution vortexed and the colour allowed to develop for $5 \mathrm{~min}$ at room temperature. Absorbance values $\left(A_{595}\right)$ were related to protein content by a calibration curve prepared using bovine serum albumin as a standard.

Chemicals. All chemicals used were AnalaR or of the highest grade available.

\section{RESULTS}

\section{Effect of glucose on long-chain alcohol production}

White et al. (1987) largely confined their study of long-chain alcohol production by C. albicans to anaerobically grown organisms. Since the media used by these workers for anaerobic and aerobic growth differed in glucose concentration, a study was made of the effect of glucose concentration on production of long-chain alcohols by this yeast. Aerobic growth in media

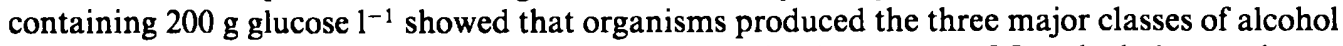
only after cessation of exponential growth (Fig. 1). While the content of $\mathrm{C}_{14}$ alcohols was always lower than those of $\mathrm{C}_{16}$ and $\mathrm{C}_{18}$ alcohols, the pattern of alcohol production differed from that encountered during anaerobic growth (White et al., 1987) in that the contents of $\mathrm{C}_{16}$ and $\mathrm{C}_{18}$ alcohols were very similar. As the concentration of glucose in media used for aerobic growth of organisms was raised from 1.0 to $30.0 \%(w / v)$, the contents of all three major classes of longchain alcohol increased in organisms from $168 \mathrm{~h}$ cultures (Fig. $2 a$ ) to a maximum total content of approximately $900 \mu \mathrm{g}$ (g dry wt organisms) $)^{-1}$. In cultures grown aerobically and containing any of the glucose concentrations, the content of $\mathrm{C}_{18}$ alcohol was slightly greater than that of the $\mathrm{C}_{16}$ alcohol and, as the glucose concentration was increased, so was the relative proportion of $\mathrm{C}_{14}$ alcohol. However, in cultures grown anaerobically for $168 \mathrm{~h}$, peak contents of each of the three alcohol classes were greatest in organisms grown in media containing $10 \%(w / v)$ glucose (Fig. $2 b$ ), the maximum being approximately $980 \mu \mathrm{g}$ (g dry wt organisms) ${ }^{-1}$. In cultures containing each of the glucose concentrations, except $1.0 \%(\mathrm{w} / \mathrm{v}), \mathrm{C}_{16}$ alcohols predominated in organisms. All cultures harvested after $168 \mathrm{~h}$ incubation had been in the stationary phase of growth for approximately the same length of time.

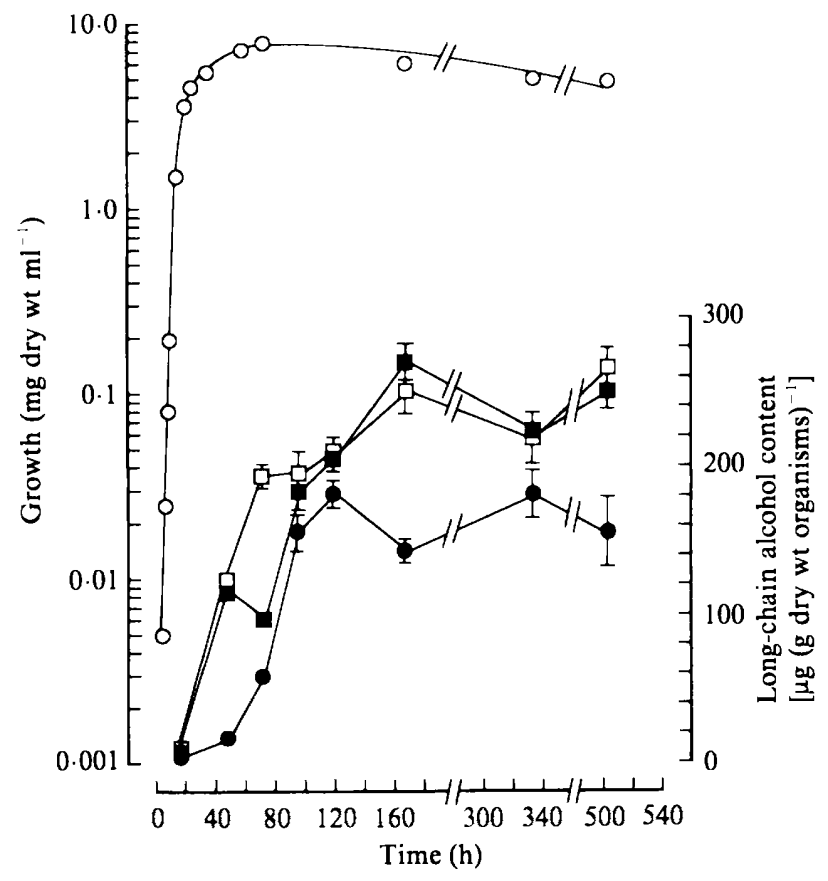

Fig. 1. Time-course of aerobic growth (O) and of synthesis of $C_{14: 0}(O), C_{16: 0}(\square)$ and $C_{18: 0}(\square)$ longchain alcohols by $C$. albicans. Values quoted are means of three independent determinations \pm SD. 

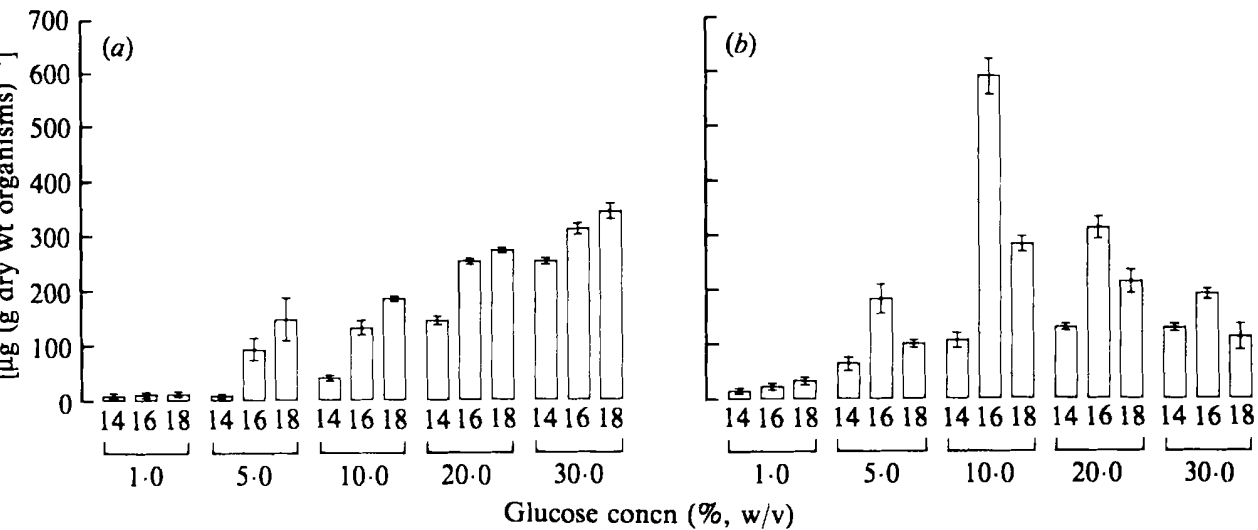

Fig. 2. Effect of glucose concentration on the long-chain alcohol contents of $C$. albicans grown aerobically $(a)$ or anaerobically $(b)$ for $168 \mathrm{~h}$. Numbers at the base of the histogram indicate the chain length of the alcohol. Each value quoted is the mean of at least three independent determinations. Bars at the top of each histogram indicate SD.

Table 1. Effect of the nature of the carbon source on the long-chain alcohol composition of Candida albicans

Organisms were grown aerobically for $168 \mathrm{~h}$. Values quoted are the means of three independent determinations $\pm S D$. ND indicates that the alcohol was not detected. Tr. indicates that a trace was detected.

\begin{tabular}{|c|c|c|c|}
\hline \multirow{2}{*}{$\begin{array}{c}\text { Carbon source } \\
(10 \%, w / v)\end{array}$} & \multicolumn{3}{|c|}{$\begin{array}{l}\text { Long-chain alcohol composition } \\
{\left[\mu \mathrm{g} \text { (mg dry wt organisms) }{ }^{-1}\right]}\end{array}$} \\
\hline & $C_{14: 0}$ & $C_{16: 0}$ & $C_{18: 0}$ \\
\hline $\begin{array}{l}\text { Glucose } \\
\text { Galactose } \\
\text { Glycerol }\end{array}$ & $\begin{array}{l}37 \cdot 1 \pm 5 \cdot 3 \\
3 \cdot 7 \pm 0 \cdot 3 \\
\text { ND }\end{array}$ & $\begin{array}{c}130.0 \pm 3.9 \\
33.7 \pm 2.7 \\
\text { Tr. }\end{array}$ & $\begin{array}{c}184 \cdot 0 \pm 11 \cdot 2 \\
95 \cdot 3 \pm 11 \cdot 2 \\
\mathrm{Tr} .\end{array}$ \\
\hline
\end{tabular}

\section{Effect of the nature of the carbon source on long-chain alcohol production}

Substituting glucose $(10 \%, \mathrm{w} / \mathrm{v})$ with the same concentration of galactose greatly decreased the content of long-chain alcohols in organisms grown aerobically for $168 \mathrm{~h}$ (Table 1). Proportionally, the effect was greatest for $\mathrm{C}_{14}$ alcohols and smallest for $\mathrm{C}_{18}$ alcohols. Replacing glucose by glycerol $(10 \%, \mathrm{w} / \mathrm{v})$ virtually abolished production of long-chain alcohols (Table 1$)$. All cultures harvested after $168 \mathrm{~h}$ incubation had been in the stationary phase of growth for approximately the same length of time.

Long-chain alcohol production in anaerobic cultures supplemented with saturated fatty acids

Organisms grown for $168 \mathrm{~h}$ in media containing $200 \mathrm{~g}$ glucose $\mathrm{l}^{-1}$ and supplemented with $10 \mathrm{mg} \mathrm{C}_{14: 0}, \mathrm{C}_{16: 0}, \mathrm{C}_{16: 1}, \mathrm{C}_{18: 0}$ or $\mathrm{C}_{18: 1}$ fatty acid ${ }^{-1}$ had the same long-chain alcohol contents as organisms grown in unsupplemented media. However, supplementing media with the oddchain fatty acids $\mathrm{C}_{13: 0}, \mathrm{C}_{15: 0}, \mathrm{C}_{17: 0}$ or $\mathrm{C}_{19: 0}$ caused the appearance of corresponding long-chain alcohols in organisms from $168 \mathrm{~h}$ anaerobically grown cultures (Table 2). These odd-chain alcohols co-chromatographed with authentic alcohol standards, and their identities were confirmed by GLC-MS (White et al., 1987). Maximum conversion of odd-chain fatty acid to the corresponding alcohol was achieved with heptadecanoic acid. There was some evidence for chain elongation and $\beta$-oxidation when shorter and longer odd-chain fatty-acid substrates were used (Table 2). The amounts of odd-chain alcohols in organisms were very small compared with the amounts of the three major even-chain alcohols. Supplementing cultures every $24 \mathrm{~h}$ with 
Table 2. Long-chain alcohol composition of Candida albicans grown in media supplemented with long-chain fatty acids

Cultures were grown anaerobically for $168 \mathrm{~h}$ in media containing $20 \%(\mathrm{w} / \mathrm{v})$ glucose and $10 \mathrm{mg}$ of the long-chain fatty acid indicated $1^{-1}$. Values quoted are the means of three independent determinations \pm SD. ND indicates that the alcohol was not detectable. Tr. indicates that a trace was detected.

\begin{tabular}{|c|c|c|c|c|c|c|c|c|}
\hline \multirow{2}{*}{$\begin{array}{l}\text { Fatty-acid } \\
\text { supplement }\end{array}$} & \multicolumn{8}{|c|}{ Long-chain alcohol composition of organisms [ $\mu \mathrm{g}$ (mg dry wt organisms) ${ }^{-1}$} \\
\hline & $C_{13: 0}$ & $C_{14: 0}$ & $C_{15: 0}$ & & $C_{17: 0}$ & $C_{18: 0}$ & $C_{19: 0}$ & Total \\
\hline $\begin{array}{l}\text { None } \\
13: 0 \\
15: 0 \\
C_{11} \\
17: 0 \\
19: 0\end{array}$ & $\begin{array}{c}\text { ND } \\
26 \cdot 3 \pm 0 \cdot 2 \\
\text { Tr. } \\
\text { ND } \\
\text { ND }\end{array}$ & & $\begin{array}{c}\text { ND } \\
22 \cdot 4 \pm 0.3 \\
28.5 \pm 1 \cdot 0 \\
\text { Tr. } \\
\text { Tr. }\end{array}$ & $\begin{array}{l}312.4 \pm 19.2 \\
296.9 \pm 6 \cdot 1 \\
319.4 \pm 14.5 \\
307.2 \pm 6 \cdot 0 \\
323.1 \pm 3.2\end{array}$ & $\begin{array}{c}\text { ND } \\
\text { Tr. } \\
\text { Tr. } \\
85.5 \pm 4 \cdot 5 \\
9 \cdot 6 \pm 1 \cdot 0\end{array}$ & $\begin{array}{l}213 \cdot 1 \pm 22 \cdot 0 \\
146 \cdot 2 \pm 5 \cdot 1 \\
206 \cdot 8 \pm 5 \cdot 8 \\
202 \cdot 4 \pm 7 \cdot 6 \\
200 \cdot 0 \pm 7 \cdot 6\end{array}$ & $\begin{array}{c}\text { ND } \\
\text { ND } \\
\text { ND } \\
\text { Tr. } \\
5 \cdot 25 \pm 0 \cdot 3\end{array}$ & $\begin{array}{l}655 \cdot 4 \pm 32 \cdot 2 \\
592 \cdot 1 \pm 4.8 \\
670 \cdot 2 \pm 22 \cdot 8 \\
728 \cdot 1 \pm 11 \cdot 6 \\
670.7 \pm 18.8\end{array}$ \\
\hline
\end{tabular}

Table 3. Effect of glucose concentration on the long-chain alcohol composition of Candida albicans grown anaerobically in cultures repeatedly supplemented with a long-chain fatty acid

Cultures were grown for $168 \mathrm{~h}$, and were supplemented every $24 \mathrm{~h}$, after the first $24 \mathrm{~h}$ incubation, with $2 \mathrm{mg} \mathrm{C} \mathrm{C}_{17: 0}$ fatty acid to a final concentration of $10 \mathrm{mg} \mathrm{l}^{-1}$. Values quoted are the means of three independent determinations \pm SD.

Concn of glucose in medium $(\%, w / v)$

1.0
5.0
10.0
20.0
30.0

\begin{tabular}{|c|c|c|c|c|}
\hline \multicolumn{5}{|c|}{ Long-chain alcohol composition of organisms $\left[\mu \mathrm{g}\right.$ (mg dry wt organisms) $\left.{ }^{-1}\right]$} \\
\hline $\mathrm{C}_{14: 0}$ & $\mathrm{C}_{16: 0}$ & $\mathrm{C}_{17: 0}$ & $\mathrm{C}_{18: 0}$ & Total \\
\hline $\begin{array}{r}6.8 \pm 0.9 \\
56.0 \pm 7.2 \\
151.9 \pm 6.4 \\
144.1 \pm 7.3 \\
124.9 \pm 19.9\end{array}$ & $\begin{array}{r}24 \cdot 0 \pm 1.8 \\
204.7 \pm 20.8 \\
427.0 \pm 4.6 \\
221 \cdot 3 \pm 10.7 \\
114.9 \pm 10.4\end{array}$ & $\begin{array}{r}31.2 \pm 6.3 \\
38.6 \pm 3.1 \\
183.8 \pm 8.6 \\
153.9 \pm 7.5 \\
62.7 \pm 8.1\end{array}$ & $\begin{array}{r}17.0 \pm 0.6 \\
134.7 \pm 16.7 \\
228.5 \pm 1.6 \\
133.2 \pm 8.1 \\
46.6 \pm 9.7\end{array}$ & $\begin{array}{r}79.0 \pm 9.5 \\
434.0 \pm 36.5 \\
994.9 \pm 14.7 \\
652.5 \pm 29.9 \\
349.1 \pm 47.2\end{array}$ \\
\hline
\end{tabular}

$2 \mathrm{mg} \mathrm{C}_{17: 0}$ fatty acid $\mathrm{l}^{-1}$ to a final concentration of $10 \mathrm{mg} \mathrm{l}^{-1}$ increased the amount of $\mathrm{C}_{17}$ alcohol synthesized (Tables 2 and 3). Moreover, the effect of glucose concentration on synthesis of $\mathrm{C}_{17: 0}$ alcohols (Table 3 ) by organisms grown anaerobically for $168 \mathrm{~h}$ was similar to the effect on production of the three major even-chain alcohols (Fig. $2 \mathrm{~b}$ ). Production of $\mathrm{C}_{17: 0}$ alcohols was least in organisms grown in medium containing $1.0 \%(\mathrm{w} / \mathrm{v})$, rose to a maximum with medium containing $10.0 \%(w / v)$ and declined with media containing more than $10.0 \%(w / v)$ glucose. Production of $\mathrm{C}_{17: 0}$ alcohols under these conditions also led to a decrease in the contents of $\mathrm{C}_{16: 0}$ and $\mathrm{C}_{18: 0}$ alcohols, while the $\mathrm{C}_{14: 0}$ alcohol content remained unaltered (Fig. 2b, Table 3).

\section{Reduction of palmitoyl-CoA to 1-hexadecanol by cell-free systems from anaerobically grown organisms}

Both microsomal and soluble protein fractions catalysed reduction of palmitoyl-CoA to 1-hexadecanol. The mean rate of production using microsomal preparations was $0.14 \pm 0.04 \mathrm{nmol} \mathrm{h}^{-1}$ (mg protein) $)^{-1}$ irrespective of whether NADH or NADPH was used as the reductant. A faster rate $\left[0.70 \pm 0.06 \mathrm{nmol} \mathrm{h}^{-1}\right.$ (mg protein) $\left.{ }^{-1}\right]$ was obtained with protein from the soluble fraction. Again, the same rate was obtained whether NADH or NADPH was used as the reductant.

\section{DISCUSSION}

The discovery that $C$. albicans, when grown anaerobically in media supplemented with oddchain saturated fatty acids, synthesized long-chain alcohols of corresponding chain length is particularly significant. When grown in the absence of fatty-acid supplements, this yeast does not synthesize odd-chain fatty-acyl residues (White et al., 1987). With most yeasts, odd-chain fatty-acyl residues are detected in their lipids only when they are grown in the presence of odd- 
chain hydrocarbons (Rattray et al., 1975; Ratledge \& Evans, 1988). In this connexion, our evidence for $\beta$-oxidation and chain elongation by organisms grown in the presence of certain odd-chain fatty acids is of considerable interest, particularly with regard to the specificity of the enzymes involved in the conversion. Our conclusion is that long-chain alcohols are synthesized in $C$. albicans by reduction of fatty acids, which can be supplied exogenously or which are synthesized endogenously as CoA esters in stationary-phase organisms that have ceased production of phospholipids, triacylglycerols and sterol esters. Naccarato et al. (1974) reported that stationary-phase cultures of Escherichia coli can convert exogenous fatty acids into longchain alcohols. White et al. (1987) suggested that long-chain alcohols synthesized by C. albicans in anaerobic cultures are secondary metabolites. Data reported here indicate that this conclusion holds also for this yeast grown under aerobic conditions.

Synthesis of long-chain alcohols by C. albicans was clearly favoured by anaerobic as compared with aerobic conditions as well as by high concentrations of glucose, both of which are conditions which repress formation of mitochondria (Käppeli, 1986). Production of these longchain alcohols might therefore be explained by the repressive conditions diverting acyl-CoA derivatives of fatty acids to reductive routes. It has been shown that many Candida species (Einsele et al., 1972; Johnson et al., 1972; Skipton et al., 1974) have a repressed oxidative metabolism when grown in the presence of high concentrations of glucose and under oxygen limitation. It is possible that the shift observed in long-chain alcohol content with different glucose concentrations, between aerobic and anaerobic conditions, could be explained by the fact that, even at very high concentrations of glucose $(10 \%, w / v)$, aerobic conditions are still less repressive than the self-induced anaerobic conditions.

The discovery that substituting galactose or glycerol for glucose in the medium greatly decreased or eliminated long-chain alcohol production suggests that alcohol synthesis is subject to carbon catabolite control. Galactose, another fermentable carbon source, is not as efficient as glucose in causing respiratory repression in C. albicans (Meyer et al., 1984). Brown \& Johnson (1970) found that higher concentrations of galactose, as distinct from glucose, were required to induce fermentative activity in Saccharomyces cerevisiae. It would, therefore, seem not unreasonable to suggest that the inefficiency of galactose in causing mitochondrial repression could be reponsible for the decreased content of alcohols in $C$. albicans grown on this substrate. Candida albicans is unable to use glycerol as a fermentable carbon source, but it is capable of respiring it (Meyer et al., 1984). That this organism would have an active respiratory system when grown on glycerol may explain its inability to synthesize significant amounts of long-chain alcohol. The finding that glucose concentration, in aerobic or anaerobic cultures, markedly affects alcohol content indicates that the regulatory effect of glucose in long-chain alcohol synthesis is complex. Synthesis of another secondary metabolite, a glycolipid, by the yeasts Torulopsis bombicola and Torulopsis magnoliae has been reported to be affected by the concentration of glucose in the growth medium (Spencer et al., 1979). Medium containing 10\% $(\mathrm{w} / \mathrm{v})$ glucose generally gave better yields than media containing lower concentrations of glucose, although the mechanism of action is unknown. Moreover, Martín (1979) reported that macrolide antibiotic biosynthesis by Streptomyces fradiae is inhibited by high concentrations of glucose. This is believed to be due to its inhibitory effect on fatty-acid degradation, the products of which act as precursors for production of these secondary metabolites. Our ability to demonstrate cell-free conversion of palmitoyl-CoA to 1-hexadecanol means that it will be possible to study experimentally the effect of glucose on synthesis and activity of the enzymes that catalyse conversion of fatty acids into long-chain alcohols in C. albicans.

M.J.W. thanks the SERC and Unilever Research for a CASE award.

\section{REFERENCES}

BrItTON, L. N. (1984). Microbial degradation of aliphatic hydrocarbons. In Microbial Degradation of Organic Compounds, pp. 89-129. Edited by D. T. Gibson. New York: Marcel Dekker.
Brown, C. M. \& Johnson, B. (1970). Influence of the concentration of glucose and galactose on the physiology of Saccharomyces cerevisiae in continuous culture. Journal of General Microbiology 64, 279-287. 
Davidova, E. G., Rachinskil, V. V. \& Kretova, L. G. (1978). Comparative study of the dynamics of carbohydrate metabolism during the growth of Candida tropicalis on n-octadecane and glucose. Mikrobiologiya 47, 799-804.

DAY, J. I. E., Goldfine, H. \& Hagen, P.-O. (1970). Enzymic reduction of long-chain acyl-CoA to fatty aldehyde and alcohol by extracts of Clostridium butyricum. Biochimica et biophysica acta 218, 179-182.

Einsele, A., Fiechter, A. \& KNÖPfel, H.-P. (1972). Respiratory activity of Candida tropicalis during growth on hexadecane and on glucose. Archiv für Mikrobiologie 82, 247-253.

Johnson, B., Nelson, S. J. \& Brown, C. M. (1972). Influence of glucose concentration on the physiology and lipid composition of some yeasts. Antonie van Leeuwenhoek 38, 129-136.

KÄPPELI, O. (1986). Regulation of carbon metabolism in Saccharomyces cerevisiae and related yeasts. Advances in Microbial Physiology 28, 181-209.

LLOYD, G. M. \& Russell, N. J. (1983). Biosynthesis of wax esters in the psychrophilic bacterium Micrococcus cryophilus. Journal of General Microbiology 129, 2641-2647.

MARTín, J.-F. (1979). Nonpolyene macrolide antibiotics. In Economic Microbiology, vol. 3, pp. 239-291. Edited by A. H. Rose. London: Academic Press.

Meyer, S. A., Ahearn, D. G. \& Yarrow, D. (1984). Candida Berkhout. In The Yeasts, a Taxonomic Study, 3rd edn, pp. 585-844. Edited by N. Kregervan Rij. Amsterdam: Elsevier Science Publishers.

Muratov, V., Bystrova, M. G., Medvedev, F. A. \& KAZANTSEV, YU. E. (1979). Isolation and identification of waxes from lipid extracts of the yeast Candida guilliermondii. Prikladnaya Biokhimiya i Mikrobiologiya 15, 383-388.

Naccarato, W. F., Gelman, R. A., Kawalek, J. C. \& GilbertsoN, J. R. (1972). Characterization and metabolism of free fatty alcohols from Escherichia coli. Lipids 7, 275-281.

Naccarato, W. F., Gilbertson, J. R. \& Gelman,
R. A. (1974). In vivo and in vitro biosynthesis of free fatty alcohols in Escherichia coli K-12. Lipids 9, 419-428.

RatLeDge, C. (1976). The physiology of mycobacteria. Advances in Microbial Physiology 13, 115-244.

RATLEDGE, C. (1978). Degradation of aliphatic hydrocarbons. In Developments in Biodegradation of Hydrocarbons, pp. 1-46. Edited by R. J. Watkinson. Barking: Applied Science Publishers.

RATLEDGE, C. \& EvaNS, C. T. (1988). Lipids and their metabolism. In The Yeasts, vol. 3, 2nd edn, pp. 367455. Edited by A. H. Rose \& J. S. Harrison. London: Academic Press.

Rattray, J. B. M., Schibeci, A. \& Kidby, D. K. (1975). Lipids of yeasts. Bacteriological Reviews 39, 197-231.

Skipton, M. D., Watson, K., Houghton, R. L. \& GrIFFITHS, D. E. (1974). A comparative study of cells and mitochondria of Saccharomyces cerevisiae and of a hydrocarbon-utilizing yeast, Candida lipolytica. Journal of General Microbiology 84, 94-110.

Spencer, J. F. T., Spencer, D. M. \& Tulloch, A. P. (1979). Extracellular glycolipids of yeasts. In Economic Microbiology, vol. 3, pp. 523-540. Edited by A. H. Rose. London: Academic Press.

White, M. J., Hammond, R. C. \& Rose, A. H. (1987). Production of long-chain alcohols by yeasts. Journal of General Microbiology 133, 2181-2190.

WiCKerhaM, L. J. (1951). Taxonomy of yeasts. I. Techniques of classification. United States Department of Agriculture Technical Bulletin no. 1029. Washington, DC: US Department of Agriculture.

ZalashKo, M. V. \& Salokhina, G. A. (1982). Intraand extracellular yeast lipids. In Biosintez $i$ Metabolizm Microorganismy, Doklady Vsesoyuznyi Konferentsiya, Second Conference 1979, pp. 23-41. Edited by A. A. Imshenetischki. A.A. Akad Nauk. Moscow, USSR: Institute of Microbiology.

Zalashko, M. V., Romanova, L. V., Gerbeda, V. V. \& PidoplichKo, G. A. (1979). Composition of extracellular lipids in the yeast Rhodotorula glutinis. Mikrobiologiya 48, 230-234. 